\title{
Untangling the interactions of sustainability targets: synergies and trade-offs in the Northern European context
}

\author{
Jari Lyytimäki ${ }^{1}$ Kirsi-Marja Lonkila ${ }^{2,3} \cdot$ Eeva Furman $^{1} \cdot$ Kaisa Korhonen-Kurki ${ }^{4}$. \\ Satu Lähteenoja ${ }^{2,5}$
}

Received: 8 April 2019 / Accepted: 7 April 2020 / Published online: 18 April 2020

(C) The Author(s) 2020

\begin{abstract}
Agenda 2030 and sustainable development goals (SDG) are key formulations of sustainability policies, consisting of 17 general-level goals and 169 more detailed targets. The target setting is based on tedious international policy negotiations and compromises addressing myriad of different and sometimes incompatible interests. Identification of key trade-offs and synergies between the targets can help the efficient implementation of SDGs by improving the opportunities to focus policy attention and actions on the most relevant issues. This article focuses on trade-offs and synergies of nationally relevant targets in the context of an industrialised and affluent nation state. Results from a cross-matrix examination of targets in Finland show that most of the selected targets are characterised by synergistic interactions with other nationally relevant targets. However, policies aimed at advancing economic growth and the use of renewable energy risk a number of serious trade-offs. Methodological advances are required to make the assessment of interactions more transparent and reliable, manageable within the limited resources and capable of producing results relevant to decision-making. A recommendation for the use of cross-matrix examination as a tool of collaborative ex ante sustainability assessment is put forward, also acknowledging the risk of "paralysis by analysis" related to the wide-ranging SDG framework.
\end{abstract}

Keywords Agenda 2030 · Ex ante assessment · Policy priorities · Sustainable development goals $\cdot$ Sustainability $\cdot$ Well-being

Jari Lyytimäki

jari.lyytimaki@ymparisto.fi

1 Finnish Environment Institute, Latokartanonkaari 11, 00790 Helsinki, Finland

2 Demos Helsinki, Helsinki, Finland

3 Ministry of the Environment, Helsinki, Finland

4 Helsinki Institute of Sustainability Science, University of Helsinki, Helsinki, Finland

5 Aalto University, Espoo, Finland 


\section{Introduction}

Policy coherence for sustainable development has become an essential part of Agenda 2030 and the architecture of sustainable development goals (SDG). Policy coherence is not an objective as such but is a means to achieve a comprehensive set of 17 SDGs. Being a strong, guiding principle for nation states, it raises expectations about the countries' performance without providing specific guidance or practical tools on how to achieve coherence between the various SDGs (Vanheukelom et al. 2018). Difficulties may arise since the SDG framework is not a logical construct based on a scientifically robust and logically coherent conceptual foundation, but is the result of international policy negotiations involving a range of actors representing different economic and policy interests, knowledge bases and cultural conceptions. Therefore, it is likely that gaps and overlaps exist within the framework (ICSU 2017; Janoušková et al. 2018). It is also obvious that implementing all the targets simultaneously with equal weights will not necessarily produce an optimal result, because of potential trade-offs between the individual targets. Furthermore, some locally or regionally relevant issues are likely to be missing from, or over-emphasised by, the framework aiming to cover key global-level issues.

The SDG framework and interactions between sustainability targets have increasingly raised political and academic interest. Several studies have focused on SDGs related to topics such as gender and equality (Stephens et al. 2018), climate change mitigation (Fuso Nerini et al. 2019), energy (Fuso Nerini et al. 2018; Santika et al. 2019) and health (Reddock 2017) and their links to other SDGs. Interactions between selected SDGs have also been scrutinised in some global assessments aimed at advising policy-making. For example, the widely debated "Global warming of $1.5^{\circ} \mathrm{C}$ " report by the International Panel on Climate Change (IPCC 2018) assessed linkages between climate change mitigation options and sustainable development using the SDGs as an organising framework. This report focused on interactions related to land use, energy supply and energy use.

Other studies have attempted to draw even more comprehensive pictures of interactions based on a variety of data sources. Le Blanc (2015) employed network analysis based on wordings of sustainability goals to identify links. While the wordings can inform about the agenda setting of policy concerns, their ability to help to identify actual impacts is limited. Pradhan et al. (2017) focused on correlations between national-level SDG indicators designed to describe all 17 SDGs. Likewise, Dörgö et al. (2018) used indicator data to evaluate the interconnectedness of SDGs. These studies are limited by the lack of reliable indicators showing the impacts of policies. Formulation of indicators aimed to describe the progress towards SDG targets is still in an early phase (Reddock 2017; Janoušková et al. 2018; Guppy et al. 2019). Another increasingly useful data source is provided by voluntary national reviews (VNR). Focusing on the first available VNRs, Tosun and Leininger (2017) noted that the links between the SDGs and the whole idea of policy integration are subject to divergent interpretations. Expert evaluations are one additional source of information. Kumar et al. (2018) incorporated experts' opinions to identify the relationships between the SDGs and the interpretive structural modelling used to develop hierarchical relationships. McGowan et al. (2019) developed a graphical model of SDG interactions based on linkages identified by experts involved in earlier assessment by ICSU (2015). Interactions can also be assessed without collecting new empirical data. For example, the Global Sustainable Development Report (GSDR 2019) draws together about two hundred global studies and assessments addressing interactions between SDG targets. 
As indicated by the above-mentioned studies and reviews of assessment methodologies and evaluation tools (Singh et al. 2012; Jordan and Turnpenny 2015; Shaker 2015; Morrison-Saunderset al. 2019), there is an increasing diversity of approaches that can be used to identify and analyse interconnections between SDGs. Such approaches range from easy-to-use check-lists and simple impact tables to technically complex modelling requiring extensive databases and advanced programming skills. The spatial focus of these approaches varies from local to global and temporal focus from immediate impacts to longterm projections. Future-oriented ex ante assessments aim to anticipate potential risks and opportunities (Nieminen and Hyytinen 2015), while in medias res assessment, or mid-term evaluation, can serve the immediate knowledge needs of adaptive management (Allan and Stankey 2009) and ex-post evaluation can verify the intended or non-intended impacts of actions (or non-action) (Nilsson et al. 2008; Lyytimäki et al. 2013). The approaches vary also in terms of participation and stakeholder involvement. Sustainability assessment methodologies highlighting multiple value positions and the need for wide-based participation as a basis of social learning have challenged those methodologies rooted on a linearrational framing of knowledge production and one-way model of science communication (Sheate and Partidário 2010; Adelle and Weiland 2012; Dunlop and Radaelli 2019).

Some types of assessments are already well-established, standardised and institutionalised-often because they are required by legislation-while others are curiosity-driven experimentations lacking wide usage. Examples of the former include methodologies for Regulatory Impact Assessment (RIA) or Strategic Environmental Assessment (SEA) that are typically mandatory processes characterised by formal procedures and rules for conducting the assessment as well as well-known target groups that are expected to use the information (Adelle and Weiland 2012). Examples of the latter include initiatives by scholars or commercial firms aiming to improve or even replace the current assessment methodologies. In addition, non-governmental organisations and other societal pressure groups may seek new assessment methods capable of producing new ammunition for societal debates. As noted by Lyytimäki et al. (2015) "political priorities such as shoring up actors' positions and maintaining control over decision-making procedures may influence the patterns of tool use in appraisal practice". Therefore, comprehensive, integrated and transparent methodologies helping to identify the key interactions between different targets are needed (Morrison-Saunders et al. 2019). Even more importantly, these methodologies should also help to create a widely shared understanding of the priorities of sustainable development.

This article answers the calls for empirical analyses on the SDG interactions and their policy implications (Nilsson 2017; Weitz et al. 2018). Outlining potential interactions is complicated because the knowledge base related to many sustainability trends and targets is patchy and limited-especially at the global level. This article focuses on the Nordic nations Finland and Sweden that are examples of countries with a relative abundance of reliable national statistical data and other information describing sustainability trends. Sweden has served as an early case country to develop and test analytical frameworks for the examination of the SDG interactions, through the typology of interactions proposed by Nilsson et al. (2016) and ICSU (2017). Weitz et al. (2018) provide a national-level analysis of interactions focusing on selected targets identified as relevant for Sweden. The first aim of this article is to test the applicability of the proposed typology and cross-impact matrix of interactions (Nilsson et al. 2016; ICSU 2017) and to compare the results describing two Nordic countries with considerable similarities but different traditions and approaches to sustainable development policies. Second, the article aims to explain the usability of the proposed cross-impact matrix in a context of national sustainability assessment, including 
potential risks for misuse of the results. More generally, the article discusses how the national-level examination of the SDG interactions can support the implementation of the Agenda 2030.

\section{Context, methods and materials}

The Nordic context is interesting for studies focusing on sustainable development since the Nordic countries often occupy the top positions in international rankings of economic, social and environmental performance. Here, the focus is on Finland and Sweden, both countries acknowledged as forerunners of the implementation of sustainable development policies (Seppälä et al. 2017; Sachs et al. 2018). The countries are characterised by strong social welfare state with corporatist elements, extensive and reliable infrastructures, advanced information and communication technologies, strong democratic institutions, low levels of corruption, high living standards and affluent lifestyles. However, both countries can also be criticised because of their high energy and natural resource consumption and because they externalise the ecological impacts of their welfare states through long production and consumption chains typical for industrialised small nation states reliant on international trade.

Here, the interactions and potential co-benefits and trade-offs of selected SDG targets in Finland are assessed and compared with earlier results describing Sweden (Weitz et al. 2018). The Finnish case study followed the methods applied for Sweden as closely as possible, to provide a solid base for country comparisons. The study was a part of the overall assessment of the Finnish sustainable development policies, providing an opportunity to test the applicability of the methodology in a real-life setting (Berg et al. 2019). The aim of the assessment was to draw a broad national-level picture based on national and international indicator data, document analysis, online surveys, expert interviews and participatory stakeholder workshops. These data were used primarily to identify national key areas of concern that guided the selection of relevant SDG targets for Finland. In addition, the eight general-level goals presented by the national sustainability strategy (FNCSD 2016) and earlier study outlining sustainability priority areas for Finland (Lyytimäki et al. 2016) were considered. The final selection of targets was negotiated between the experts who performed the assessment. The national relevance of the target was the main selection criterion. Other criteria included the expertise available for the assessment and unambiguous formulation of the target that would allow for a meaningful assessment.

To allow a comprehensive assessment given the limited resources available, only one nationally relevant target was selected to represent each SDG. As noted by Weitz et al. (2018), covering all 169 targets and how they interact is not feasible in most cases. The selection of 17 targets produces 272 relationships for the analysis. The final selection of targets is presented in Table 1. Targets were adopted directly from the SDG framework without clarifying their sometimes-complicated wording or adjusting their focus according to the national conditions or concerns.

The 17 key targets selected for Finland were organised into a cross-impact matrix of $17 \times 16$ interactions by which the impact of a row variable affects the column variable. The presentation format allows visualisation of the results through colour coding illustrating the seven-point typology of interactions (Nilsson et al. 2016; Nilsson 2017; ICSU 2017). The typology includes interactions characterised as cancelling $(-3)$, counteracting $(-2)$, constraining $(-1)$, consistent $(0)$ when there is no significant interaction, enabling $(+1)$, 
Table 1 Nationally relevant SDG targets identified for the assessment

Targets selected for the assessment ${ }^{\mathrm{a}}$

Correspondence with national

priorities $^{\mathrm{a}}$

1.2 By 2030, reduce at least by half the proportion of men, women and children of all $\mathbf{5}, 7,8$ ages living in poverty in all its dimensions according to national definitions

2.4 By 2030, ensure sustainable food production systems and implement resilient agricultural practices that increase productivity and production, that help maintain ecosystems, that strengthen capacity for adaptation to climate change, extreme weather, drought, flooding and other disasters and that progressively improve land and soil quality

3.5 Strengthen the prevention and treatment of substance abuse, including narcotic drug abuse and harmful use of alcohol

4.7 By 2030, ensure that all learners acquire the knowledge and skills needed to promote sustainable development, including, among others, through education for sustainable development and sustainable lifestyles, human rights, gender equality, promotion of a culture of peace and non-violence, global citizenship and appreciation of cultural diversity and of culture's contribution to sustainable development

5.5 Ensure women's full and effective participation and equal opportunities for leadership at all levels of decision-making in political, economic and public life

6.6 By 2020, protect and restore water-related ecosystems, including mountains, forests, wetlands, rivers, aquifers and lakes

7.2 By 2030, increase substantially the share of renewable energy in the global energy mix

8.1 Sustain per capita economic growth in accordance with national circumstances and, in particular, at least $7 \%$ gross domestic product growth per annum in the least developed countries

9.4 By 2030, upgrade infrastructure and retrofit industries to make them sustainable, with increased resource-use efficiency and greater adoption of clean and environmentally sound technologies and industrial processes, with all countries taking action in accordance with their respective capabilities

10.1 By 2030, progressively achieve and sustain income growth of the bottom $40 \%$ of the population at a rate higher than the national average

11.6 By 2030, reduce the adverse per capita environmental impact of cities, including by paying special attention to air quality and municipal and other waste management

12.3 By 2030, halve per capita global food waste at the retail and consumer levels and reduce food losses along production and supply chains, including post-harvest losses

13.1 Strengthen resilience and adaptive capacity to climate-related hazards and natural disasters in all countries

14.1 By 2025, prevent and significantly reduce marine pollution of all kinds, in particular from land-based activities, including marine debris and nutrient pollution

15.5 Take urgent and significant action to reduce the degradation of natural habitats, halt the loss of biodiversity and, by 2020 , protect and prevent the extinction of threatened species

16.6 Develop effective, accountable and transparent institutions at all levels

8, $5,7,6$

17.3 Mobilise additional financial resources for developing countries from multiple sources

${ }^{a}$ Nationally relevant priority areas used as criteria for target selection: (1) sustainability of energy system, (2) sustainable use of forests, (3) sustainability of water ecosystems, (4) sustainable food system, (5) social equality and inclusiveness, (6) sustainable development and Finnish cross-sectoral foreign policy, (7) renewal of employment and economic policy, (8) policy leadership and mechanisms of sustainable development. Primary priority areas are indicated in bold 
reinforcing $(+2)$, and indivisible $(+3)$. The typology is largely consistent with that proposed earlier as an evaluation tool in the 2009 national sustainable development assessment of Finland and further developed in a report published in 2011 (Ramboll 2009; Lyytimäki 2011). However, this evaluation tool has not been used.

Each interaction was assessed according to expert elicitation with an evaluation question: "If progress is made on certain targets (rows), how does this influence the progress of other targets (columns)?" The cross-impact matrix was first independently filled in by experienced experts from several disciplinary backgrounds (environmental sciences, policy studies, environmental policy, political science, sustainability science and geography) $(N=6)$. Individual initial evaluations were used to identify interactions with the greatest differences between expert judgements. Most of these differences were related to unclear formulations of the target, different background assumptions related to policy implementation and differences in inclusion of indirect effects of implementation. All judgements were critically discussed in a common session and a matrix filled in with mean values calculated from individual expert judgements adjusted until a consensus view was reached. The results were used to as one data source to assess the policy coherence of Finnish sustainable development policies (Berg et al. 2019).

The scoring process was qualitative and partially based on subjective valuations and expectations of future developments. Expert evaluation as a method is widely used in a range of studies, particularly in environmental sciences (e.g. Hathout et al. 2019; Chrysafi et al. 2019), sustainability assessment (e.g. Seppälä et al. 2017) and future studies (e.g. Tapio et al. 2011; Honda et al. 2017). Expert judgments are used particularly when there is not enough evidence or data to explain certain phenomenon or when a probabilistic understanding of the phenomenon is required (Kontic 2000). Expert evaluation is always characterised by subjectivity as people are subject to values which are partially based on the experiences they have had, and this will influence the way people make the evaluations (Wilkins 2003). Nevertheless, expert evaluation can produce reliable information when it is done properly: meeting the requirements of replicability, traceability and being unbiased (Wilkins 2003). In the present case, the independent individual assessments helped to avoid the danger of group-thinking and revealed the interactions with greatest differences in expert opinions. The joint face-to-face discussion for reaching the consensus view was crucial for the validity of the judgement since it allowed the clarification of reasons for differences. The key issues were the weights given to impacts occurring in near or distant future and inclusion of secondary or indirect impacts of actions. Potential changes in external environment were not taken into consideration when specific interactions were considered.

\section{Results}

The summary of the assessment of the nature of selected interactions between the key SDG targets in a Finnish context is presented in Fig. 1. Detailed results are presented in Fig. 2. The colour coding is aimed to give an overall picture of how successful implementation of certain targets (row variable) affects the implementation of other targets (column variables), according to the expert evaluations. The numerical row sums indicate the level of influence of a target on other targets. A high sum implies that successful implementation of a target is likely to advance the implementation of several other targets. A negative row sum would indicate that implementation of a target generally 


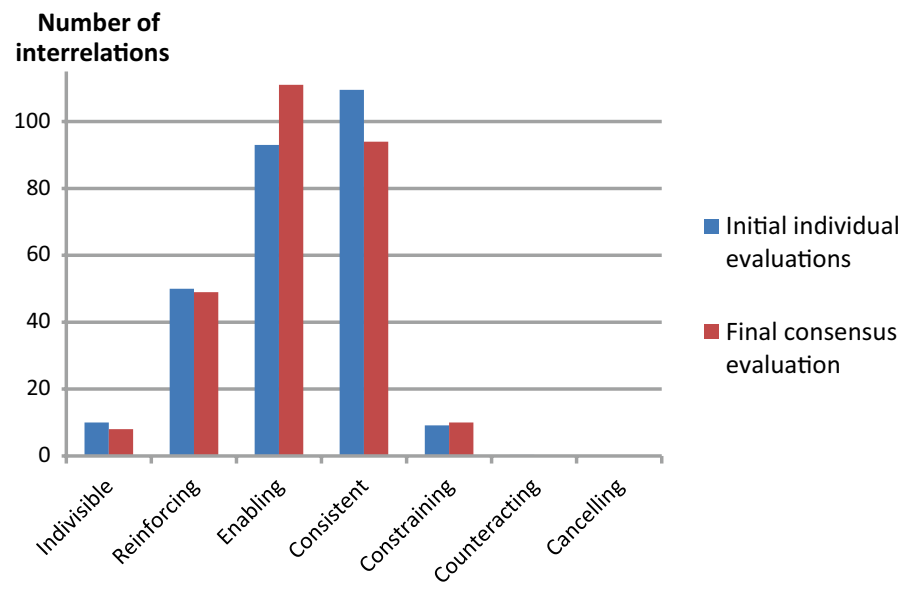

Fig. 1 Summary of interrelations between nationally relevant SDG targets

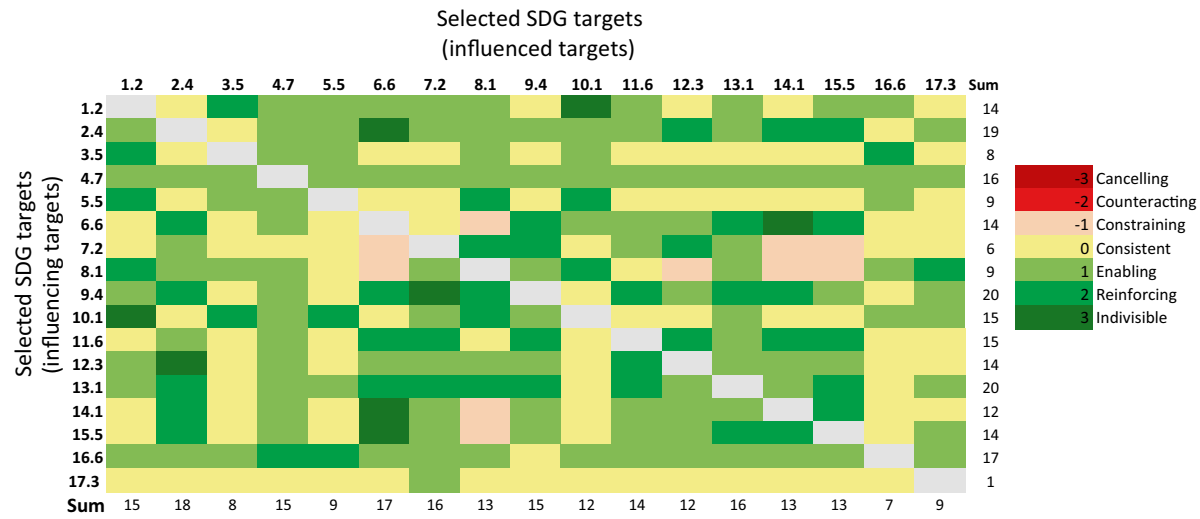

Fig. 2 Assessment of interactions between nationally relevant SDG targets

hampers the implementation of other targets. Both low and high row sums suggest that a special attention should be directed to the implementation to the target in question. However, the sum values are indicative, and they should not be looked at in isolation because they may include considerable uncertainties and mask countering impacts.

The high number of relationships classified as consistent suggests that many activities reaching a target can be implemented without major implications for other targets. Some targets were characterised by a particularly high proportion of consistent relationships. Several reasons were identified for this. Target 3.5 focusing on substance abuse is relatively narrowly defined. Therefore, it has direct major impacts on few other sustainability issues. The high proportion of consistent relationships can also indicate an overly vague formulation of the target, potentially resulting from political compromises (Vandemoortele 2018). Target 5.5 focusing on gender equality and participation by women on societal issues is loosely defined and is a wide topic that has direct or indirect connections with most of the other targets. 
Identification of connections turned out to be highly dependent on the assumptions made by the evaluator. Therefore, the transparency of the process and open communication between the evaluators are vital for trustworthiness of the evaluation. In some cases, the ambiguous formulation of a global target makes it difficult to make a meaningful assessment of interactions. For example, assessment of potential impacts related to target 7.3 (double the global rate of improvement in energy efficiency by 2030) turned out to be too challenging in a national setting and target 7.2 was assessed instead. Target 4.7 focusing on the education of and for sustainable development was also challenging to evaluate. It is a good example of a target that has wide-ranging effects on the long-term implementation of other targets, but chains of impacts might be long, hard to track and might appear only after a delay of decades. Even though the concept of sustainable development is integrated into the Finnish education system, its practical role remains secondary in most schools, vocational education and university-level education (Åhlberg et al. 2015; Wolff et al. 2017). For example, there are serious gaps in the ecological know-how of students in vocational training (Räkköläinen et al. 2017). More generally, however, a high-quality education system can be considered to be an important enabling factor for the long-term implementation of all other SDG targets.

The results of the assessment were largely in line with earlier research pointing out the dominance of synergistic relationships within the SDG framework (e.g. ICSU 2017; Weitz et al. 2018). Eight relationships within the Finnish case were classified as "indivisible", implying that successful implementation of the target would likely lead to reaching other targets. These relationships were distributed evenly among the targets suggesting that policy attention should be given to a large group of targets instead of focusing only on certain critical ones. Judged from the row sums, targets 9.4, 13.1 and 2.4 are characterised by many synergistic effects. Target 9.4 focusing on the development of infrastructure and technology provides specific opportunities for an information-intensive and technologically advanced country such as Finland. Target 13.1 emphasises sociotechnical resilience and the relatively advantageous position of Finland related to climate change adaptation. Climate change adaptation supports the long-term implementation of other targets, even though short-term economic implications may be negative for current energy-intensive industries or lifestyles. Developing a more sustainable food system (target 2.4) was considered to provide opportunities for an agricultural sector currently suffering from the double dilemma of poor economic performance and high environmental impact. Sustainable food systems also entail changes in current consumption patterns.

The column sums indicate how a target is influenced by the implementation of other targets. Protection of inland waters (target 6.6) strongly benefits from other activities, especially those focusing on food system (target 2.4) and environmental protection (targets 14.1 and 15.5). However, policies supporting the increased use of renewable energy (target 7.2) may increase pressures to water ecosystems especially because of more intensive use of forests in bioenergy production (Kangas et al. 2018).

Target 16.6 on efficient, responsible and transparent institutions was identified as a target that is generally not positively influenced by the implementation of other targets (low row sum) but that enables or reinforces the implementation of almost all other targets (high column sum). Strong democratic institutions and high level of transparency, including low level of corruption, have also elsewhere been identified as strengths of the Finnish society and-more widely - the Nordic societal system (Berg et al. 2019).

Cancelling and counteracting interactions were missing completely from the assessment, suggesting that implementation of the nationally relevant SDG targets is possible without major societal conflicts of interests. However, ten constraining relationships were 
identified, especially related to targets 7.2 and 8.1. The target 7.2 focuses on renewable energy. Wood is currently the most important source of renewable energy in Finland. The wording of the target is about increasing the global proportion of renewable energy but the evaluation focused on potential implications at a national level. In addition to influencing negatively water quality (targets 6.6 and 14.1), biodiversity is likely to be negatively influenced (target 15.5). Target 8.1 on sustaining per capita economic growth was interpreted as a continuation of the current patterns of economic growth, characterised by wide-based and intensive use of natural resources. Therefore, potential impacts of economic growth on environment and natural resources were emphasised.

The results of the Swedish assessment (Weitz et al. 2018) are generally consistent with the Finnish results. Ten of the targets chosen for Finland were also assessed in the Swedish case. Both assessments ranked targets $2.4,9.4,13.1$ and 16.6 as highly synergistic and capable of supporting the implementation of other targets. Some differences were also identified. Notably, target 5.5 (ensure women's full and effective participation and equal opportunities) is seen as highly synergistic in the Swedish assessment, whereas in the Finnish case, synergistic effects appear to be weaker. This may reflect different expert interpretations of the effects to be included into the assessment rather than real differences in women's participation between the two countries.

\section{Discussion}

Indivisibility-understanding that the SDGs and their targets are fundamentally interdependent—is strongly highlighted by Agenda 2030. Earlier assessments generally suggest that most of the relationships within the SDG framework are synergistic ones: activities aiming to reach one goal or target tend to improve, directly or indirectly, opportunities to reach other goals or targets. But there are also risks of collateral damages (Le Blanc 2015; Tosun and Leininger 2017; Dörgö et al. 2018; Kumar et al. 2018; GSDR 2019). Various trade-offs have been identified, and often there is a masking effect caused by the parallel existence of synergies and trade-offs. For example, increasing the proportion of renewable energy (SDG7) with forest-based bioenergy may help to replace fossil fuels and mitigate climate change (SDG13), but at least temporarily it might reduce forest carbon sinks and cause other harmful environmental effects (SDG14, SDG15) (Kangas et al. 2018). This makes impact assessment and the associated public and policy debate complicated.

Various lessons related to the operationalisation of this indivisibility can be derived from the results presented here, both related to the SDG framework and the assessment methodology. The first lesson is about the notion of indivisibility itself. The SDG framework that addresses a wide variety of societal concerns and presents numerous targets on a one-to-one basis is likely to lead to an isolated treatment of individual targets, rather than systemic treatment taking the interdependencies into account. Several authors have criticised the siloed approach addressing SDGs as separate elements as well as the incoherent structure of SDG framework and demanded a robust theory-based framework to organise sustainability transition (ICSU 2015; Le Blanc 2015; Spangenberg 2016). Such a conceptual framework would be useful for organising national-level sustainability assessment.

However, it is likely that building a logical and comprehensive conceptual framework that identifies and fully captures all relevant dimensions of sustainable development is a mission impossible. This is due to several reasons. First, as indicated by the results from the Nordic countries, the knowledge base remains inherently patchy and characterised by 
a range of uncertainties. Second, new knowledge needs and emerging issues arise continuously because of changes in both ecosystems and societies (Munn et al. 1999). Third, and perhaps most importantly, identification of societally relevant sustainability issues and their key interactions is fundamentally a value choice, often involving political bargaining. Finally, our results support earlier observations that sustainability frameworks can involve considerable omissions even when they are designed to be comprehensive (Leukhardt and Allen 2013; Spangenberg 2016; McGowan et al. 2019). Thus, the complexity and incoherence of the SDG framework should be accepted as an inevitable reflection of the multifaceted nature of sustainable development. Assessment methods need to be designed in a way that they can effectively address such imperfections.

Attention to the integration of various forms of expertise is clearly needed if the SDG framework is to be used as a basis for a sustainability assessment. The experiences from the Finnish case showed that both the practical and conceptual challenges of this integration can be considerable. The large number of interactions resulting from the extensive and all-compassing SDG framework makes the assessment complicated. Limiting the number of SDGs and targets may help to improve the reliability of the assessment but at the same time, there is a risk that the validity of the assessment suffers because some relevant interactions may remain unnoticed. Resources are needed to overcome the communicational challenges caused by disciplinary boundaries and to build a consensus view combining different value perspectives and knowledge bases. In particular, when the resources for the assessment are limited, it may be difficult to recruit a strong pool of knowledgeable and motivated experts willing to share their time and expertise.

Several factors complicated the assessment. Selecting the SDG targets that have the highest resonance with the national key concerns was challenging, and other selections could have been justified. This uncertainty about the appropriate selection of targets was not considered to be critical for the analysis since the main aim was not to prioritise individual targets but to assess the nature of their interactions. Second, because of lack of clear formulations of several SDG targets, assumptions had to be made about the specific meaning of the wordings of targets in a national context. The original wordings were used to maintain international comparability even though this often complicates national-level interpretations. Targets better adapted to national contexts and policy concerns could make the assessment more easy to perform and more policy relevant, but outlining and agreeing on such targets requires a separate process.

The different temporal focus of the targets complicated the assessment. 2030 was generally taken as the reference year, but three of the selected targets specifically mentioned a target year other than 2030. As a rule, experts put more weight on impacts that were likely in the near future. Despite the common guidelines adopted from earlier studies (ICSU 2017; Weitz et al. 2018), expert-based assessment inevitably includes differences in interpretations and produced some variability to the assessment. Therefore, tailoring a clear guidance focusing on the specific case and applying a procedure allowing and encouraging open discussion about differences in interpretations is a necessity. Finding the appropriate balance between impacts to be included or excluded turned out to be especially difficult. As a rule, only impacts causally related to the national-level implementation of the target at hand were included. For practical reasons, this was necessary, but the choice is problematic since policy coherence for sustainable development should be assessed wider than in national "closed" context (Vanheukelom et al. 2018).

These challenges should not be seen only as obstructions but also as opportunities. The need for integration of expert views also provides opportunities for social learning. In the Finnish case, the learning was mainly based on a face-to-face discussion allowing 
for a critical but constructive exchange of viewpoints. Some major opportunities to improve the assessment process were identified. First, the reliability of the assessment could be improved through a wider pool of experts, supported by facilitation of face-toface interaction and more extensive use of existing data sources. However, increasing the number of experts involved faces serious practical challenges, especially if plentiful financial resources for the assessment are missing.

Expert judgements could be complemented with data-intensive approaches utilising SDG indicators or other data. Currently, the lack of readily available indicators is a key obstacle to reliable assessment. For example, the national-level SDG indicators for Finland were released in February 2019 but about a half (47\%) of indicators were without data (Statistics Finland 2019). It is expected that the data coverage will be improved. Global SDG indicators are continuously developed by the United Nations' Inter-Agency and Expert Group on SDG Indicators (IAEG-SDGs). Other indicator applications may also provide useful information for the assessment of interlinkages. Others have proposed alternative global indicator sets (e.g. Sachs et al. 2018), employed an SDG framework to select indicators describing a specific region (Eurostat 2018) or described the performance of organisations under the SDG framework (GRI 2017). Also, socalled big data applications and modelling approaches provide interesting opportunities to complement or even replace expert assessment (Campagnolo et al. 2018). A key strength of the expert elicitation is the ability to induce versatile discussion about the limits, strengths and weaknesses of the SDG framework itself. Making this discussion and the assessment process more transparent, available and appealing for wider audiences remains a key challenge. Use of online tools designed to bring different expert views together could help the learning process and increase the transparency and replicability of the process.

Second, besides sustainability assessment, the methodology can also serve other purposes. Social learning could be enhanced by adopting a transdisciplinary approach emphasising knowledge co-creation combining academic and expert insights with other stakeholder views (Huutoniemi and Tapio 2014). There is strong demand for hands-on tools for building a more coherent picture of SGD performance built in Agenda 2030 and the SDGs (target 17.14). The cross-matrix methodology is being developed to become a tool that could be used in a transdisciplinary learning process by experts from various domains and sectors in order to a build common understanding of the interactions between SDGs (Stockholm Environment Institute 2018). The approach could have value in bringing together government stakeholders from different sectors with the scientific community and provide a platform to discuss often politically sensitive and value-laden interactions in a clear framework.

Some applications already exist. Using the methodology in a narrower setting or in one sector could provide better results. In Sweden, the steel industry interest organisation has used the methodology in the organisation's foresight process (Hallding and Blixt 2017). At the national level, the methodology has been trialled in Mongolia and Sri Lanka (Stockholm Environment Institute 2018). In the Sri Lankan context, the methodology was tested by a local think tank and the United Nations Development Program, but key ministries were involved in the process. The aim was to provide support for national policy-making. Based on the experiences from these studies and the Finnish case, it is crucial to create strong ownership by selecting the right targets with the key stakeholders and thus limiting their number. This way, the framework could provide support for countries in prioritisation of their SDG work (Allen et al. 2019). For example, the methodology could be used for setting priorities and supporting national policy planning and budgeting, as well as building 
collaboration between different actors. It can also be used to check or assess mid-term or post-term performance in the implementation of SDGs.

Creating a shared understanding of the cause/effects is a key precondition for the reliable assessment of interactions. The experiences from the Finnish case showed that even experts sharing a similar disciplinary background may have variable conceptions of the relevant interactions, as highlighted by the differences in initial assessments made independently by each expert. In this case, group discussion focusing on the reasons for these differences turned out to be an efficient way to create a mutual understanding of the specific meaning of the targets. However, if a wider pool of evaluators is involved, finding common ground is likely to be difficult. Further complications are created by the SDG framework including the targets. For example, the SDG framework does not distinguish between process-oriented targets and outcome-oriented targets.

Different actors are likely to have a different perception of the existence and type of relationships between SDG targets. Some of this variability could be avoided by a more precise formulation of the targets. The wording of the targets was strongly criticised during the Finnish assessment process, and formulations better suited to consider the specific features of the national context were called for. The importance of adjusting the target setting according to the national priorities is also noted in Agenda 2030. However, the risk is that as the context sensitivity is improved, the international comparability and transparency will decrease.

As indicated by the high proportion of "consistent" relationships both in this study and in the Swedish case (Weitz et al. 2018), the relationships are often indirect and difficult to discern. Earlier studies such as the network analysis by Le Blanc (2015) also noted that the level of interconnectedness between the targets varies considerably. Some targets appear to be well connected, while others remain more or less isolated. However, when considered over a long time frame, the indirect or weak links between targets may also turn out to be relevant. Therefore, directing too much policy attention to direct short-term effects may be counterproductive in the long term; especially regarding the long-term perspective, nonlinear changes continue to be a key challenge for the assessment because of potential thresholds between alternative states of systems.

\section{Conclusions}

A key motivation for the assessment of interactions is to identify the potential missing links or overemphasised areas of action, to avoid unintentional or purposeful misuse of SDG framework. The assessment of interactions may help to identify synergistic solutions that can be keys to several problems. The results from the Finnish and Swedish assessments suggest that such "policy champions" are hard to find, at least in the context of the Nordic nations. The results caution against focusing narrowly on any individual target. Instead, there is a need for wide-based actions focusing on several targets and SDGs. Furthermore, the results suggest that widely accepted policies aimed at securing economic growth are prone to producing non-intended negative effects on other sustainability goals. It should be noted that the situation may be different in those countries in the Global South struggling to satisfy the basic needs of the population.

Achieving all 169 global SDG targets formulated under the framework of Agenda 2030 is a daunting task even for the Nordic countries with relatively abundant economic resources, wide availability of data and relatively high public and policy awareness of 
sustainability issues. Successful assessment of priority areas and potential synergies and trade-offs between different targets can help to provide effective guidance to the activities aimed at advancing sustainability. The results from this study suggest that the key question in the Nordic countries is not so much about finding a single target to rule them all, but it is about the wide-based societal endeavour to tackle the complicated interplay of various targets of more or less equal importance. Further studies are needed to show whether it is easier to find single SDG targets that represent priority areas with high vulnerabilities or opportunities in other countries.

Based on this study and earlier adoptions in various contexts, the success and usability of the assessment methods of SDG interactions depends on three main elements. First, participants (whether from civil society, business, policy or science domains) should feel ownership of the selection and interpretation of the targets chosen for analysis. Second, a wide range of policy sectors should be committed to the process. Third, the methodology is often rather heavy and should be further developed into a lighter version in order to motivate participation. Balance needs to be reached in being inclusive, comprehensive and strongly supported by evidence, at the same time avoiding being too complex or time-consuming.

The SDG framework provides many opportunities for different kinds of assessment. Therefore, it also entails a risk of "paralysis by analysis" where different assessments are produced and discussed but where they remain unused or are used only in a ritualistic manner instead of effectively guiding the policy. Comprehensive and detailed analysis of interactions of all 169 targets is most likely to be neither possible nor meaningful for national-level policy-making. A more realistic goal for ex ante sustainability assessment of interactions is to provide decision-makers with an understanding of whether there are justifications to focus attention on implementation of a specific SDG goal or target and whether there are risks of major harmful effects or the potential for synergies.

The assessment framework and the assessment of interactions provide a platform for building a common understanding between actors from different policy sectors. Adjustment of SDG targets according to the national context is advisable do the assessment will be more reliable and policy-relevant. Developing the assessment towards a more focused participatory process aimed at supporting social learning with targeted stakeholder groups such as policy-makers and industry representatives provides considerable opportunities for connecting SDGs with nationally relevant concerns.

Acknowledgements Open access funding provided by Finnish Environment Institute (SYKE).

Funding Funding was provided by Strategic Research Council (Grant No. 327768).

Open Access This article is licensed under a Creative Commons Attribution 4.0 International License, which permits use, sharing, adaptation, distribution and reproduction in any medium or format, as long as you give appropriate credit to the original author(s) and the source, provide a link to the Creative Commons licence, and indicate if changes were made. The images or other third party material in this article are included in the article's Creative Commons licence, unless indicated otherwise in a credit line to the material. If material is not included in the article's Creative Commons licence and your intended use is not permitted by statutory regulation or exceeds the permitted use, you will need to obtain permission directly from the copyright holder. To view a copy of this licence, visit http://creativecommons.org/licenses/by/4.0/. 


\section{References}

Adelle, C., \& Weiland, S. (2012). Policy assessment: The state of the art. Impact Assessment and Project Appraisal, 30(1), 25-33. https://doi.org/10.1080/14615517.2012.663256.

Åhlberg, M. K., Aineslahti, M., Alppi, A., Houtsonen, L., Nuutinen, A. M., \& Salonen, A. (2015). Education for sustainable development in Finland. In R. Jucker \& R. Mathar (Eds.), Schooling for sustainable development in Europe (pp. 221-239). Cham: Springer.

Allan, C., \& Stankey, G. H. (Eds.). (2009). Adaptive environmental management. Dordrecht: Springer.

Allen, C., Metternicht, G., \& Wiedmann, T. (2019). Prioritising SDG targets: Assessing baselines, gaps and interlinkages. Sustainability Science, 14, 421-428. https://doi.org/10.1007/s11625-018-0596-8.

Berg, A., Lähteenoja, S., Ylönen, M., Korhonen-Kurki, K., Linko, T., Lonkila, K-M., Lyytimäki, J., Salmivaara, A., Salo, H., Schönach, P., \& Suutarinen, I. (2019). PATH2030-An evaluation of Finland's sustainable development policy. Publications of the Government's analysis, assessment and research activities 2019:23. Prime Minister's Office, Helsinki.

Campagnolo, L., Carraro, C., Eboli, F., Farnia, L., Parrado, R., \& Pierfederici, R. (2018). The ex-ante evaluation of achieving sustainable development goals. Social Indicators Research, 136(1), 73-116. https://doi.org/10.1007/s11205-017-1572-X.

Chrysafi, A., Cope, J. M., \& Kuparinen, A. (2019). Eliciting expert knowledge to inform stock status for data-limited stock assessments. Marine Policy, 101, 167-176. https://doi.org/10.1016/j.marpo 1.2017.11.012.

Dörgö, G., Sebestyén, V., \& Abonyi, J. (2018). Evaluating the interconnectedness of the sustainable development goals based on the causality analysis of sustainability indicators. Sustainability, 10, 3766. https://doi.org/10.3390/su10103766.

Dunlop, C. A., \& Radaelli, C. M. (2019). Policy instruments, policy learning and politics: Impact assessment in the European union. In G. Capano, M. Howlett, M. Ramesh, \& A. Virani (Eds.), Making policies work first- and second-order mechanisms in policy design (pp. 115-136). Cheltenham: Edward Elgar.

Eurostat. (2018). Sustainable development in the European Union. Monitoring report on progress towards the SDGs in an EU context, 2018 edition. Luxembourg: Publications Office of the European Union. https://doi.org/10.2785/401485.

FNCSD. (2016). The Finland we want by 2050-Society's commitment to sustainable development. Finnish National Commission on Sustainable Development. Retrieved February 6, 2019, from https ://kestavakehitys.fi/en/commitment2050.

Fuso Nerini, F., Sovacool, B., Hughes, N., Cozzi, L., Cosgrave, E., Howells, M., et al. (2019). Connecting climate action with other sustainable development goals. Nature Sustainability, 674, 674-680. https://doi.org/10.1038/s41893-019-0334-y.

Fuso Nerini, F., Tomei, J., To, L. S., Bisaga, I., Parikh, P., Black, M., et al. (2018). Mapping synergies and trade-offs between energy and the sustainable development goals. Nature Energy, 3, 10-15. https://doi.org/10.1038/s41560-017-0036-5.

GRI. (2017). Measuring progress on the SDGs. Summary of results. Retrieved February 6, 2019, from https://www.globalreporting.org/resourcelibrary/sdg-indicator-mapping.pdf.

GSDR. (2019). Global sustainable development report 2019: The future is now-Science for achieving sustainable development. New York: United Nations.

Guppy, L., Mehta, P., \& Qadir, M. (2019). Sustainable development goal 6: Two gaps in the race for indicators. Sustainability Science, 14, 501-513. https://doi.org/10.1007/s11625-018-0649-z.

Hallding, K., \& Blixt, E. (2017). A societal value compass for the Swedish steel industry. Retrieved February 6, 2019, from https://mediamanager.sei.org/documents/Publications/SEI-FS-2017-Socie tal-value.pdf.

Hathout, M., Vuillet, M., Carvajal, C., Peyras, L., \& Diab, Y. (2019). Expert judgments calibration and combination for assessment of river levee failure probability. Reliability Engineering \& System Safety. https://doi.org/10.1016/j.ress.2019.03.019.

Honda, H., Washida, Y., Sudo, A., Wajima, Y., Awata, K., \& Ueda, K. (2017). The difference in foresight using the scanning method between experts and non-experts. Technological Forecasting and Social Change, 119, 18-26. https://doi.org/10.1016/j.techfore.2017.03.005.

Huutoniemi, K. I., \& Tapio, P. (Eds.). (2014). Transdisciplinary sustainability studies: A heuristic approach. London: Routledge.

ICSU. (2015). Review of the sustainable development goals: The science perspective. Paris: International Council for Science.

ICSU. (2017). A guide to SDG interactions: From science to implementation. Paris: International Council for Science. https://doi.org/10.24948/2017.01. 
IPCC. (2018). Summary for policymakers. Global warming of $1.5^{\circ} \mathrm{C}$. International Panel on Climate Change. Retrieved February 6, 2019, from https://www.ipcc.ch/sr15/chapter/summary-for-polic y-makers/.

Janoušková, S., Hák, T., \& Moldan, B. (2018). Global SDGs assessments: Helping or confusing indicators? Sustainability, 10(5), 1540. https://doi.org/10.3390/su10051540.

Jordan, A. J., \& Turnpenny, J. R. (Eds.). (2015). The tools of policy formulation: Actors, capacities, venues and effects. Cheltenham: Edward Elgar.

Kangas, H.-L., Lyytimäki, J., Saarela, S.-R., \& Primmer, E. (2018). Burning roots: Stakeholder arguments and media representations on the sustainability of tree stump extraction in Finland. Biomass and Bioenergy, 118, 65-73. https://doi.org/10.1016/j.biombioe.2018.08.006.

Kontic, K. (2000). Why are some experts more credible than others? Environmental Impact Assessment Review, 20, 427-434. https://doi.org/10.1016/S0195-9255(00)00057-3.

Kumar, P., Ahmed, F., Singh, R. K., \& Sinha, P. (2018). Determination of hierarchical relationships among sustainable development goals using interpretive structural modelling. Environment, Development and Sustainability, 20(5), 2119-2137. https://doi.org/10.1007/s10668-017-9981-1.

Le Blanc, D. (2015). Towards integration at last? The sustainable development goals as a network of targets. Sustainable Development, 23, 176-187. https://doi.org/10.1002/sd.1582.

Leukhardt, F., \& Allen, S. (2013). How environmentally focused is the German sustainability strategy? A critical discussion of the indicators used to measure sustainable development in Germany. Environment, Development and Sustainability, 15(1), 149-161. https://doi.org/10.1007/s10668-012-9380-6.

Lyytimäki, J. (2011). Kestävään kehitykseen liittyvien vaikutusten ennakkoarviointi politiikansuunnittelussa ja päätöksenteossa. Ympäristöministeriön raportteja 24/2011. Helsinki: Ympäristöministeriö. https:// hdl.handle.net/10138/41443

Lyytimäki, J., Lähteenoja, S., Sokero, M., Korhonen, S., \& Furman, E. (2016). Agenda 2030 in Finland: Key questions and indicators of sustainable development. Publications of the Government's analysis, assessment and research activities 32/2016. Helsinki: Prime Minister's Office. https://tietokayttoon.fi/ julkaisu?pubid $=13401$.

Lyytimäki, J., Söderman, T., \& Turnpenny, J. (2015). Knowledge brokerage at the science-policy interface: New perspectives on tools for policy appraisal. Environmental Science and Policy, 51, 313-315. https ://doi.org/10.1016/j.envsci.2015.05.007.

Lyytimäki, J., Tapio, P., Varho, V., \& Söderman, T. (2013). The use, non-use and misuse of indicators in sustainability assessment and communication. International Journal of Sustainable Development and World Ecology, 20(5), 385-393. https://doi.org/10.1080/13504509.2013.834524.

McGowan, P. J. K., Stewart, G. B., Long, G., \& Grainger, M. J. (2019). An imperfect vision of indivisibility in the sustainable development goals. Nature Sustainability, 2, 43-45.

Morrison-Saunders, A., Sánchez, L., Retief, E., Sinclair, F., Doelle, J., Jones, M., et al. (2019). Gearing up impact assessment as a vehicle for achieving the UN sustainable development goals. Impact Assessment and Project Appraisal. https://doi.org/10.1080/14615517.2019.1677089.

Munn, T., Timmerman, P., \& Whyte, A. (1999). Emerging environmental issues: A global perspective of SCOPE. Ambio, 28(6), 464-471.

Nieminen, M., \& Hyytinen, K. (2015). Future-oriented impact assessment: Supporting strategic decision-making in complex socio-technical environments. Evaluation, 21(4), 448-461. https://doi. org/10.1177/1356389015606540.

Nilsson, M. (2017). Important interactions among the sustainable development goals under review at the high-level political forum 2017. Working Paper 2017-06. Stockholm: Stockholm Environment Institute.

Nilsson, M., Griggs, D., \& Visbeck, M. (2016). Map the interactions between sustainable development goals. Nature, 534(7607), 320-322. https://doi.org/10.1038/534320a.

Nilsson, M., Jordan, A., Turnpenny, J., Hertin, J., Nykvist, B., \& Russel, D. (2008). The use and non-use of policy appraisal tools in public policy making: An analysis of three European countries and the European Union. Policy Sciences, 41(4), 335-355. https://doi.org/10.1007/s11077-008-9071-1.

Pradhan, P., Costa, L., Rybski, D., Lucht, W., \& Kropp, J. P. (2017). A systematic study of sustainable development goal (SDG) interactions. Earth's Future, 5, 1169-1179. https://doi.org/10.1002/2017E F000632.

Räkköläinen, M., Metsämuuronen, J., \& Kiesi, J. (2017). Kestävän kehityksen osaaminen, opetus ja koulutuksen järjestäjän toiminta ammatillisissa perustutkinnoissa. Kansallinen koulutuksen arviointikeskus, julkaisut 12:2017. Tampere: Juvenes Print.

Ramboll. (2009). Kansallinenkestävänkehityksenarviointi 2009. Helsinki: Ramboll Consulting Management \& Ympäristöministeriö. 
Reddock, J. (2017). Seeking consensus on universal health coverage indicators in the sustainable development goals. Journal of Health Services Research \& Policy, 22(3), 178-182. https://doi. org/10.1177/1355819617704676.

Sachs, J., Schmidt-Traub, G., Kroll, C., Lafortune, G., \& Fuller, G. (2018). SDG index and dashboards report 2018. New York: Bertelsmann Stiftung and Sustainable Development Solutions Network (SDSN).

Santika, W. G., Anisuzzaman, M., Bahri, P. A., Shafiullah, G. M., Rupf, G. A., \& Urmee, T. (2019). From goals to joules: A quantitative approach of interlinkages between energy and the sustainable development goals. Energy Research \& Social Science, 50, 201-214. https://doi.org/10.1016/j. erss.2018.11.016.

Seppälä, J., Leskinen, P., \& Myllyviita, T. (2017). Expert panel weighting and aggregation of the sustainable society index (SSI) 2010-A decision analysis approach. Sustainable Development, 25, 322-335. https ://doi.org/10.1002/sd.1659.

Shaker, R. R. (2015). The spatial distribution of development in Europe and its underlying sustainability correlations. Applied Geography, 63, 304-314. https://doi.org/10.1016/j.apgeog.2015.07.009.

Sheate, W. R., \& Partidário, M. R. (2010). Strategic approaches and assessment techniques-Potential for knowledge brokerage towards sustainability. Environmental Impact Assessment Review, 30(4), 278288. https://doi.org/10.1016/j.eiar.2009.10.003.

Singh, R. K., Murty, H. R., Gupta, S. K., \& Dikshit, A. K. (2012). An overview of sustainability assessment methodologies. Ecological Indicators, 15(1), 281-299. https://doi.org/10.1016/j.ecolind.2011.01.007.

Spangenberg, J. H. (2016). Hot air or comprehensive progress? A critical assessment of the SDGs. Sustainable Development, 25(4), 311-321. https://doi.org/10.1002/sd.1657.

Statistics Finland (2019). UN indicators for sustainable development (Agenda 2030). Retrieved March 1, 2019, from https://www.stat.fi/tup/kestavan-kehityksen-yk-indikaattorit-agenda2030_en.html.

Stephens, A., Lewis, E. D., \& Reddy, S. (2018). Towards an inclusive systemic evaluation for the SDGs: Gender equality, environments and marginalized voices (GEMs). Evaluation, 24(2), 220-236. https:// doi.org/10.1177/1356389018766093.

Stockholm Environment Institute. (2018). Applying the SDG interactions framework: preliminary lessons learnt. In Policy coherence for sustainable development 2018: Towards sustainable and resilient societies (pp. 101-103). Paris: OECD Publishing. https://doi.org/10.1787/9789264301061-en.

Tapio, P., Paloniemi, R., Varho, V., \& Vinnari, M. (2011). The unholy marriage? Integrating qualitative and quantitative information in Delphi processes. Technological Forecasting and Social Change, 78, 1616-1628. https://doi.org/10.1016/j.techfore.2011.03.016.

Tosun, J., \& Leininger, J. (2017). Governing the interlinkages between the sustainable development goals: Approaches to attain policy integration. Global Challenges, 1(9), 1700036. https://doi.org/10.1002/ gch2.201700036.

Vandemoortele, J. (2018). From simple-minded MDGs to muddle-headed SDGs. Development Studies Research, 5, 83-89. https://doi.org/10.1080/21665095.2018.1479647.

Vanheukelom, J., Mackie, J., \& Ronceray, M. (2018). Good enough coherence? Six lessons from good governance for policy coherence and the 2030 Agenda. ECDPM. Retrieved February 6, 2019, from https://ecdpm.org/publications/good-enough-coherence-six-lessons-from-good-governance-for-polic y-coherence-2030-agenda/.

Weitz, N., Carlsen, H., Nilsson, M., \& Skånberg, K. (2018). Towards systemic and contextual priority setting for implementing the 2030 Agenda. Sustainability Science, 13, 531-548. https://doi.org/10.1007/ s11625-017-0470-0.

Wilkins, H. (2003). The need for subjectivity in EIA: Discourse as a tool for sustainable development. Environmental Impact Assessment Review, 23, 401-414. https://doi.org/10.1016/S0195-9255(03)00044-1.

Wolff, L.-A., Sjöblom, P., Hofman-Bergholm, M., \& Palmberg, I. (2017). High performance education fails in sustainability?-A reflection on finnish primary teacher education. Education Sciences, 7(1), 32. https://doi.org/10.3390/educsci7010032.

Publisher's Note Springer Nature remains neutral with regard to jurisdictional claims in published maps and institutional affiliations. 